\title{
When Joy Matters: The Importance of Hedonic Stimulation in Collocated Collaboration with Large-Displays
}

\author{
Jasminko Novak and Susanne Schmidt \\ Dept. of Informatics, University of Zurich, Binzmühlestrasse 14, 8050 Zurich, Switzerland \\ \{novak, schmidt\}@ifi.uzh.ch
}

\begin{abstract}
Hedonic aspects are increasingly considered as an important factor in user acceptance of information systems, especially for activities with high self-fulfilling value for the users. In this paper we report on the results of an experiment investigating the hedonic qualities of an interactive large-display workspace for collocated collaboration in sales-oriented travel advisory. The results show a higher hedonic stimulation quality of a touch-based large-display travel advisory workspace than that of a traditional workspace with catalogues. Together with the feedback of both customers and travel agents this suggests the adequacy of using touch-based large-displays with visual workspaces for supporting the hedonic stimulation of user experience in collocated collaboration settings. The relation of high perception of hedonic quality to positive emotional attitudes towards the use of a large-display workspace indicates that even in utilitarian activities (e.g. reaching sales goals for travel agents) hedonic aspects can play an important role. This calls for reconsidering the traditional divide of hedonic vs. utilitarian systems in current literature, to a more balanced view towards systems which provide both utilitarian and hedonic sources of value to the user.
\end{abstract}

Keywords: Collaboration, large displays, hedonic information systems, user experience.

\section{Introduction}

Hedonic aspects of system use (joy of use) are increasingly considered as an important factor in user acceptance of information systems, especially for activities with high self-fulfilling value $[5,16,10]$. Thereby, the investigation of hedonic aspects is often biased towards systems supporting user activities which are hedonic by nature (e.g. entertainment, games [12]). This is reflected in a distinction between hedonic and utilitarian systems, which differentiates between the satisfaction of self-fulfilling user needs (hedonic) and activities in which functional, pragmatic goals are in the foreground. While such a distinction may be suitable in certain occasions, here we discuss the role of hedonic aspects in activities which are utilitarian by nature.

In particular, we report on the results of an experiment investigating the role of hedonic aspects in designing interactive large-display visual workspaces for collocated collaboration in the domain of travel advisory - an issue barely examined in existing 
work. Face-to-face advisory is a special class of collocated collaboration in which an expert advisor interacts with the customer in creating a personalized offering of a product or service (e.g. travel planning, financial services) [24]. In contrast to online sales which target high-volume transactions with relatively simple and wellunderstood needs, face-to-face consultations target the sales of complex products, where customer needs are difficult to formulate and translate to a tailored solution [24]. While utilitarian concerns motivate the activity (finding a suitable vacation at suitable cost), emotional aspects of the product (vacation) and user experience of the process play an important role.

The use of large displays for group interaction has been studied in two main areas: 1) supporting group awareness and collaboration in the workplace [3, 20,28] and 2) supporting social interaction and media sharing in (semi)public settings [17]. Examples include coordination of small groups in the medical domain [32], the use of large-displays for large-scale collaboration in NASA control rooms [15, 29] and in classrooms [8]. Earlier work also considered requirements and guidelines for single display groupware in collocated collaboration [27], but little work specifically examined the role and support for hedonic aspects, "the joy of use". The existence of two different components (hedonic and utilitarian) in user attitudes towards the use of information systems has been evidenced already in [1], but few empirical studies successfully verified this in specific domains. Huang [14] found that web-sites must fulfill both information-related and hedonic, often entertainment-related needs. Studies of hedonic and utilitarian aspects of user attitude in business management software [25] and online retail shopping behavior [2] point to similar findings.

\section{Hedonic vs. Utilitarian Information Systems}

Task-related qualities like perceived usefulness and perceived ease of use have been widely studied and recognized as crucial concepts explaining the user acceptance of information systems [5, 6]. Perceived usefulness reflects the user's belief that "using a specific application system will increase his or her job performance within an organizational context" [11] i.e. that the provided functionality will fulfill the needs for accomplishing given tasks. Perceived ease of use reflects the user's belief of an effortless usage of functionality. Related system characteristics are thus task-related qualities $[10,9]$ and provide the user with instrumental value i.e. they are of a utilitarian nature [12].

While a number of studies have confirmed this approach, the importance of perceived enjoyment has been highlighted in studies where it has played a greater role in system acceptance than perceived usefulness and ease of use [19, 30]. Perceived enjoyment refers to "the extent to which the activity of using the computer is perceived to be enjoyable in its own right, apart from any performance consequences that may be anticipated" [5, p. 1113]. Therefore, enjoyment can be assumed to be a factor for intrinsic motivation. This notion has also been described with the term hedonic, referring to the concept of hedonism as a doctrine in which pleasure is the primary goal of existence [18]. As a result, information systems tend to be divided along two main lines: between approaches emphasizing the primacy of functional (task-related) aspects and those focusing on the user experience of the process. 
The former are also referred to as utilitarian systems which aim at "providing instrumental value to the user" [12], while the latter are denoted as hedonic systems where value for the user comes from his self-fulfillment in using the system [12]. Utilitarian systems address tasks and activities where user motivation in using the system is driven by the expectation of a reward or benefit external to his interaction with the system [12]. On the other hand, hedonic systems serve activities in which users are intrinsically motivated by benefits stemming from the interaction with the system as such, rather than task-related outcomes of their interactions [12]. As a result, the primary design objective of utilitarian systems is productive use whereas for hedonic systems it is prolonged use of the system [12].

However well supported by different studies, such distinction seems overly sharp. On one hand, a natural goal of each system design is to encourage prolonged user acceptance. On the other hand, studies such as [10] suggest that task-unrelated qualities of software systems are an essential element in explaining system acceptance. Stimulating overall enjoyment and "joy of use" can encourage users not only to develop a positive attitude towards system use but to entice a lasting usage. Especially in the field of HCI, the importance of designing for "joy of use" rather than only for functional usefulness and ease-of-use as an important driver of user satisfaction and system acceptance has been increasingly recognized in research and practice $[16,10]$. In this view, successful systems are conceived not only in terms of user efficiency in fulfilling their task, but also in terms of user enjoyment in the process as their integral part [10]. In everyday life, this has been vividly demonstrated with the success of digital consumer devices (e.g. iPod, iPhone). In spite of diverging views emphasising the primacy of efficiency and control [13], the importance of hedonic aspects has been empirically demonstrated for the design of systems mediating the satisfaction of intrinsically hedonic user needs (e.g. finding movies to watch) [12]. Though most of these findings apply to activities of a hedonic nature, they suggest that even in utilitarian activities, it may be important to consider hedonic aspects as an essential design objective. The next sections discuss this issue in collocated travel advisory.

\section{Emotional Collaboration in Face-to-Face Travel Advisory}

The elicitation of customer needs and their mapping to product features is the main pragmatic challenge addressed by sales-oriented travel advisory in a face-to-face setting [24]. User preferences are "sticky": difficult to elicit and to be described, evolving with the perceived possibilities from the solution space. On one hand, effective solution of this problem requires overcoming the intrinsic information asymmetry in which only the agent has access to all relevant solution space information (travel database, Internet) (Fig. 1).

On the other hand, sales advisory is not merely about pragmatic problem-solving: it is also a highly emotionally colored process. Customer criteria can rapidly change based on impressions of presented alternatives and especially so in travel advisory: a terrific photograph, a compelling video or a funny anecdote can swiftly shift customer desires and create emotional bonds to destinations or to the agent. The problemsolving process is intertwined with an emotional dimension of the consulting experience: desires are stirred, moods awaken and in this situation a decision process is 


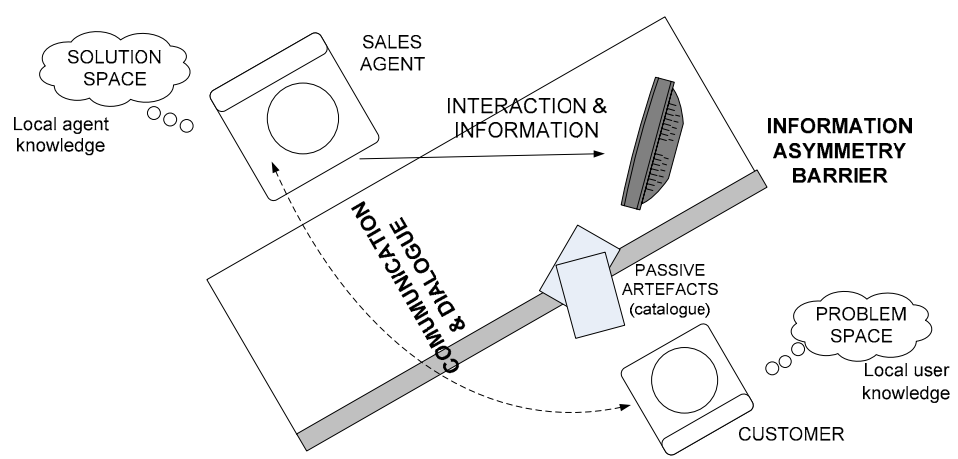

Fig. 1. Traditional travel advisory setting [21]

carried out. We refer to this as "emotional collaboration" [23]. This suggests a high importance of hedonic quality for travel advisory systems: though seeking professional travel advisory is a highly utilitarian activity (effectively finding suitable vacation offers in a desired price range), underlying user motivations for searching travel products and undertaking a vacation are intrinsically hedonic (e.g. enjoyment, relaxation, adventure). Accordingly, making the process of devising a personal itinerary an enjoyable experience - rather than a time consuming activity of shifting through loads of impersonal information - is likely to achieve higher customer satisfaction.

Achieving high customer satisfaction has an even greater importance for offline travel agencies: they are under great pressure to provide added-value services which distinguish them from purely online competition that offers easy access to a vast range of travel offerings, literally at the users' fingertips [22]. At the same time, pragmatic aspects such as the identification and creation of offers matching personal preferences under suitable economic conditions as well as the trustworthiness of the information and of the travel agent also play an important role in the decision process [4]. Thus, we argue that designing systems to successfully support face-to-face travel consultancy requires considering both the pragmatic aspects of overcoming the obstacles of effective customer-agent collaboration [21] and the hedonic aspects of overall user experience.

\section{Design Principles and Hedonic Aspects of a Prototype System}

Our concept for addressing these issues is based on two main design goals: 1) reducing information asymmetry through shared visualization and 2) heightening emotional user experience ("joy of use"). Both of these are addressed by introducing a touchsensitive large-display (a Smartboard ${ }^{1}$ ) with an interactive, visual travel advisory system. The first is expected to improve the problem-solving process (eliciting customer needs and constructing appropriate solutions) and increase the trustworthiness of the setting while the latter is aimed at facilitating the process by increasing emotional user stimulation and satisfaction. Our concrete solution is depicted in Figure 1.

${ }^{1{ }^{\circledR}}$ Smart Technologies, http://smarttech.de 


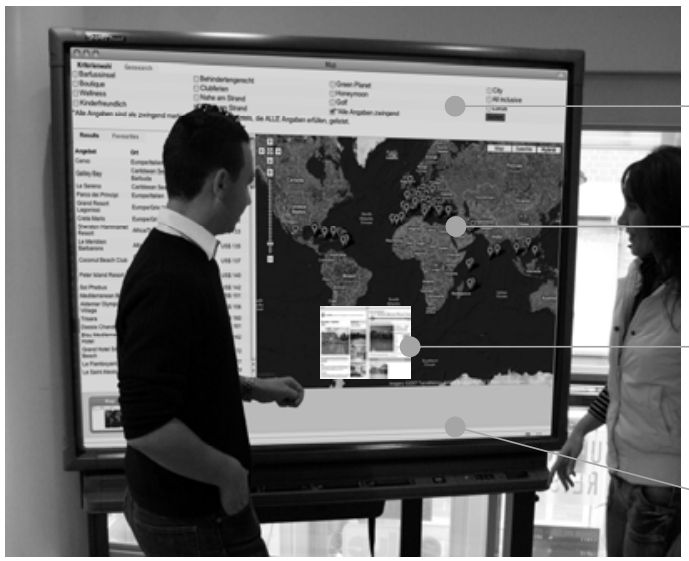

Shared problem definition space: selection criteria and search queries

Shared visualisation of the solution space:

geographic view of matching offers

Official and community information: user ratings and vacation reports (photos, videos...)

Visual history: thumbnails of inspected offers

Fig. 2. Cooperative travel advisory system based on a touch-sensitive large display [23]

As the user-centered design process and the system functionalities have been described in $[23,26]$, we only briefly outline the main aspects.

The physical arrangement is such that the customer and the sales agent stand in front of a large, touch-sensitive display. Large displays lend themselves readily to providing a shared visual workspace that can be inspected jointly by both participants. In contrast to multiple small screens with a single mouse interaction [24] this allows natural interaction for both participants (dragging and selecting with bare hands) and natural coordination of access to the shared screen (pointing, gesture). Above all, their visual qualities are ideal for amplifying emotional impact, while touch-interaction provides not only a natural interaction method but also stimulates sensory experience.

The travel advisory application provides a visual overview of the travel products on offer, contextualized on a geographic map (Google Maps). This travel space can be searched and browsed by different criteria and includes multimedia information both from official travel agency database and user-generated content from Internet portals and communities. Details of the developed travel advisory application and how it supports the pragmatic functionalities (e.g. shared view on information resources, proactive user exploration, user-generated content) are described in $[23,26]$. To further user's emotional engagement the system takes advantage of multimedia (photos, videos) on the large screen. Due to the physical arrangement (customer and agent standing in front of the screen) and the screen size the user is engulfed in the visual experience. The closeness to the display invites active involvement. As reflected in user comments, this stimulates hedonic experience by capturing attention, providing exciting novel functionalities and easy access to otherwise unavailable content [11].

\section{Experimental Evaluation: Pragmatic vs. Hedonic Qualities}

The results of a first evaluation of this design concept in a proof-of-concept prototype suggested that functional qualities of the system and the user experience are superior 
to the traditional setting $[23,26]$. They exhibited a high user preference for the consultancy with the large-display workspace (10 of 12 users). The informal feedback pointed out user excitement about the visual qualities of the large-display and the experience of touch-based interaction [23]. User observation also suggested emotional experience as a possible factor of user satisfaction and system acceptance. Accordingly, we undertook a second experiment in order to investigate hedonic qualities in more detail. To this end we employed the AttrakDiff 2 questionnaire for elicitation of perceived hedonic quality [11] accompanied by the UTAUT questionnaire for elicitation of user attitude to using the system [31].

\subsection{Investigating the Role of Hedonic Quality}

In order to determine the hedonic qualities of an interactive system the AttrakDiff2 instrument [11] differentiates between pragmatic and hedonic qualities as independent constructs determining the overall perception of the attractiveness of a system $[9,10]$. Pragmatic quality (PQ) refers to the perceived quality of manipulation (i.e. effectiveness and efficiency of use). Hedonic quality (HQ) is described in terms of hedonic stimulation (HQ-S) and hedonic identity (HQ-I). The stimulation quality refers to the extent to which the system stimulates the innate human need for personal development (e.g. new skills and knowledge). By offering exciting functionalities, content or interaction styles, a system can heighten the user's attention, overcome motivational barriers or ease a problem-solving process [11] - thus supporting effective task completion and further usage. The identity aspect refers to addressing a personal need of expressing oneself and being perceived by others in a certain way [11]. As people commonly express themselves through personal objects (e.g. clothes, jewelry, mobiles), the functionalities, design or visual appearance of a system can relate to a user's need for communicating a certain identity. In the operationalization users are asked to rate the system on 7 semantic differentials (Table 1) for each construct with a 7-point Likert-scale.

Table 1. Semantic differentials of hedonic stimulation (HQ-S) and pragmatic quality (PQ) [11]

\begin{tabular}{lll}
\hline Indicator for & positive part & negative part \\
\hline HQ-S & challenging & harmless \\
HQ-S & exciting & dull \\
HQ-S & creative & uninspired \\
HQ-S & inventive & conventional \\
HQ-S & novel & usual \\
HQ-S & innovative & conservative \\
HQ-S & courageous & careful \\
\hline PQ & practical & unpractical \\
PQ & manageable & unmanageable \\
PQ & predictable & unpredictable \\
PQ & clearly & confusing \\
PQ & directly & awkward \\
PQ & humanly & technical \\
PQ & simple & complicated \\
\hline
\end{tabular}


In line with the prior discussion we stated the following hypotheses ${ }^{2}$ :

H1.1: The hedonic stimulation quality of the touch-sensitive large-display workspace perceived by the customers is higher than that of the traditional travel consultancy workspace.

H1.2: The hedonic stimulation quality of the touch-sensitive large-display workspace perceived by the travel agents is higher than that of the traditional travel consultancy workspace.

H2.1: The pragmatic quality of the touch-sensitive large-display workspace perceived by the customers is higher than that of the traditional travel consultancy workspace.

H2.2: The pragmatic quality of the touch-sensitive large-display workspace perceived by the travel agents is higher than that of the traditional travel consultancy workspace.

\subsection{Experiment Design}

The experiment involved 22 customers divided in two groups in a between-subjects design: one group of 11 participants performed a vacation planning task (planning an activity holiday) in the traditional consultancy setting while the other group of 11 participants performed the same task with the large-display workspace. We have chosen a between-subjects design to exclude any possible carry-over effects and user strain noticed in the first test. The sessions were conducted by 4 travel agents in the traditional and 5 agents in the large-display setting.

The system used in the traditional setting was comprised out of a standard PC with the travel agency database (incl. photos and videos), Internet access and print catalogues (Figure 1). The experiment took part in a real-world travel agency specialized in individual and student travel. The participants were randomly recruited from the agency's clients and through postings on a university forum (each received a 150 CHF travel discount voucher). They were between 21-37 years of age with high proficiency in computer use $(80 \%)$ and both groups having the same composition regarding participants' sex (36\% female, 64\% male).Travel agents received a 30mins hands-on training with the system. Customers received no training. The sessions were limited to 30mins (duration of a typical advisory session). All received the AttrakDiff2 questionnaire [11] based on a 5-point Likert-scale ${ }^{3}$.

\subsection{Results}

The results are depicted in Figure 3. We considered both hypotheses for customers and agents. The data was tested with a two-sided t-test for samples with differing variances. The results indicate a statistically significant $(\mathrm{p}<0.05, \mathrm{df}=17, \mathrm{t}=3.61)$ higher hedonic stimulation (HQ-S) for the large-display workspace (HQ-Savg $=4$ vs. 3.17) regarding customers. This confirms the hypothesis H1.1. The difference in

\footnotetext{
${ }^{2}$ We don't consider hedonic identity (HQ-I) since the system doesn't provide means for the user to communicate a personal identity to other people. For HQ-I constructs see [10].

3 The 5-point Likert-scale was employed in order to keep a uniform scale design across all questionnaires in the experiment (others addressed issues not subject of this paper).
} 

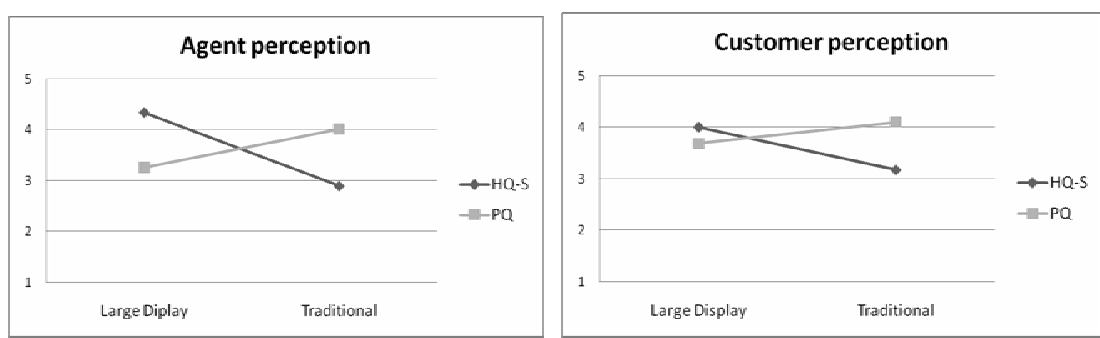

Fig. 3. Pragmatic and hedonic qualities of the large-display vs. traditional workspace
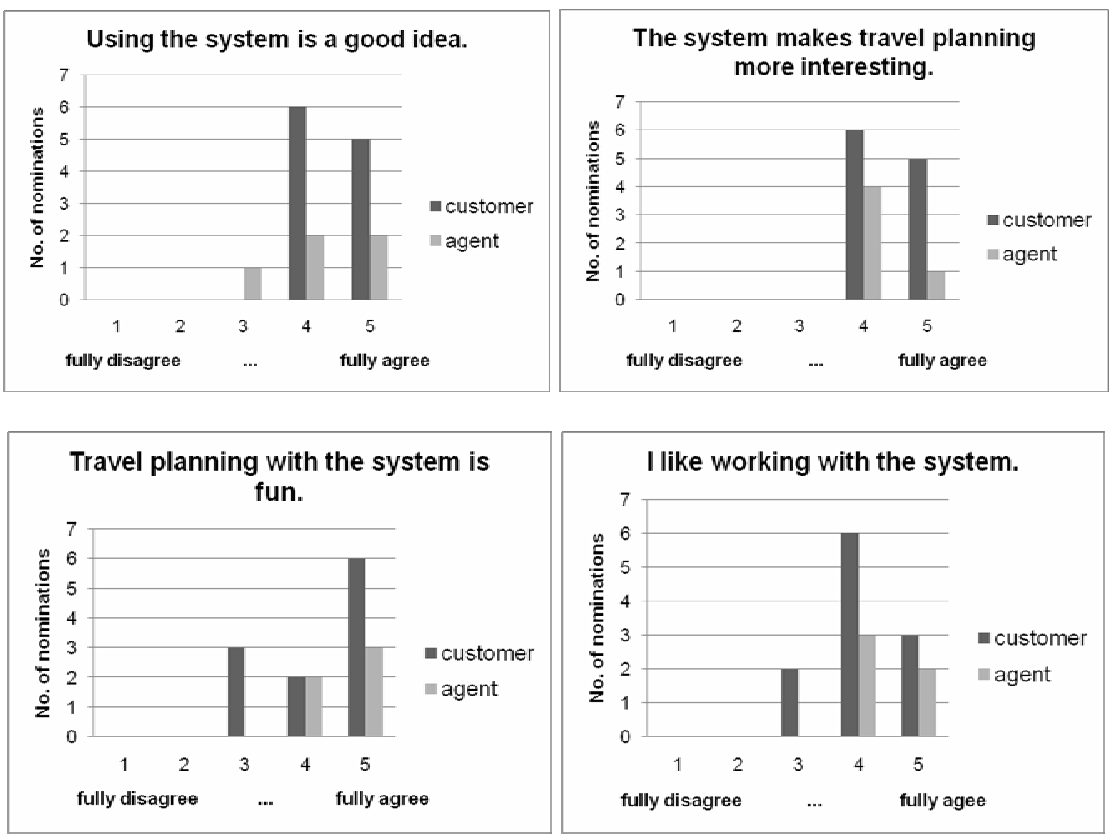

Fig. 4. Results of the UTAUT questionnaire regarding attitude towards using the system

pragmatic quality $(P Q)$ is statistically significant regarding customers $(\mathrm{p}<0.05, \mathrm{df}=20$, $\mathrm{t}=-3.21$ ) but lower for the large-display workspace (PQavg =3.67 vs. 4.1). This refutes $\mathrm{H} 2.1$.

Agents also rate a higher hedonic stimulation (HQ-Savg=4.34 vs. 2.89) for the large-display workspace. The difference is statistically significant $(\mathrm{p}<0.05, \mathrm{df}=5$, $\mathrm{t}=8.05$ ). This confirms H1.2. The lower perception of pragmatic quality for the largedisplay workspace by the travel agents (PQavg=3.25 vs. 4.01) is in line with the lower pragmatic quality perceptions of the customers, but not statistically significant. Thus $\mathrm{H} 2.2$ could not be validated in either sense.

The results of the UTAUT questionnaire (Figure 4) indicate the positive attitude towards using the system both for customers and travel agents. All customers and all but one agent considered using the system to be a good idea, while all of them 
perceived the system making travel planning more interesting. All agents and the majority of customers (72.7\%) liked working with the system and considered travel planning with the system to be fun (all agents, $81.8 \%$ customers).

\subsection{Discussion and Limitations}

Given no other differences between the two travel advisory workspaces, such results suggest that the use of a touch-sensitive large-display with a visual workspace leads to a higher hedonic stimulation. The lower pragmatic quality of the large-display workspace compared to the traditional setting additionally supports this interpretation. As the elicited pragmatic qualities (e.g. manageable, practical, simple, see Table 1) relate to the perceived ease of using the system in accomplishing the given task, the overall positive user attitudes towards the system (like working with, makes travel planning more interesting etc., Figure 4), can be related to its task-unrelated aspects i.e. hedonic quality. Since effective support of hedonic aspects is an important requirement of this problem class (as argued in introductory sections) this implies that using touchsensitive large-displays is a good design choice for interactive visual workspaces in travel advisory. Coupled with informal user feedback highlighting the visual qualities and touch-based interaction, these findings also suggest that touch-based largedisplays with a highly visual interactive application seem to exhibit intrinsic qualities of hedonic stimulation. This also makes them an interesting choice for other application domains in which hedonic stimulation and emotional collaboration play an important role.

The results of the travel agent perceptions point to another interesting observation. Though their motivation for using travel advisory support systems (e.g. booking systems, catalogues, internet) is highly utilitarian by nature (reaching their individual sales goals effectively and efficiently), their responses indicate a high perception of hedonic quality and positive emotional attitudes towards the large-display system (makes fun to use, like working with). This indicates that even in utilitarian activities (e.g. travel sales from the agents' point of view) hedonic aspects of the supporting system can play an important role in user attitude. This suggests that the existing distinction in literature between utilitarian and hedonic information systems [12], each providing a different source of value to the user (self-fulfilling vs. instrumental) should be reconsidered towards a more balanced view including a class of systems combining both sources of value.

A likely cause for lower perception of pragmatic quality of the large-display workspace (contradicting a previous trial [23]) may be the lack of proficiency of agents in using the system and in adapting it to their advisory practice. In fact, one limitation of the validity of the results is that though explicitly asked to rate the large-display workspace the participants may not have entirely differentiated between this system and their overall impression of the advisory process.

In other words, the high ease-of-use and the ease of learning to use the system with the large display (reported in [23]), do not automatically translate into effective advisory process in the new, technologically-enhanced setting. In contrast, the advising process in the traditional setting is well established with extensive experience of the 
agents. This is likely to lead to a higher user perception of the advisory process effectiveness. This suggests the need for a new advisory process, better taking advantage of pragmatic functionalities offered by the system. Such a new process may emerge from agent self-learning through more extensive use of the system in advisory practice or it could be developed and trained in advance. Here, we can only speculate that this may increase the perception of pragmatic quality. But we can exclude a possible influence of this factor on hedonic stimulation since hedonic quality of the traditional setting in which advisors are more proficient was significantly lower than that of the large-display system. Hence, advisor training could only further improve this difference to the advantage of the new system.

\section{Conclusions}

In this paper we have discussed the importance of hedonic qualities for interactive systems supporting collocated collaboration in utilitarian activities such as sales-oriented travel advisory. The results of our experiment show a higher hedonic stimulation quality of a touch-based large-display cooperative travel consultancy workspace than that of a traditional advisory setting. Coupled with qualitative user feedback highlighting the visual qualities and touch-based interaction, this suggests intrinsic hedonic stimulation qualities for large-display visual workspaces. This makes them a suitable design choice for supporting collocated collaboration in expertcustomer sales consultancies as well as an interesting medium for other application domains with high importance of hedonic factors. Finally, the results indicate that even in utilitarian activities (e.g. travel sales from the agents' point of view) hedonic aspects can play an important role in user attitude towards system use. This calls for considering a "new" class of hybrid systems which combine pragmatic and hedonic sources of value for the user.

\section{References}

1. Batra, R., Ahtola, O.T.: Measuring the hedonic and utilitarian sources of consumer attitudes. Marketing Letters 2(2), 159-170 (1991)

2. Childers, T.L., Carr, C.L., Peck, J., Carson, S.: Hedonic and utilitarian motivations for online retail shopping behavior. Journal of Retailing 77(4), 511-535 (2001)

3. Churchill, E.F., Nelson, L., Denoue, L.: Multimedia Fliers: Information Sharing With Digital Community Bulletin Boards. In: Proc. of Communities and Technologies 2003 (2003)

4. Coulter, K.S.: The Effects of Travel Agent Characteristics on the Development of Trust: A Contingency View. Journal of Travel\&Tourism Marketing 11(4), 67-85 (2002)

5. Davis, F.D., Bagozzi, R.P., Warshaw, P.R.: Extrinsic and Intrinsic Motivation to Use Computers in the Workplace. Journal of Applied Social Psychology 22(14), 1111-1132 (1992)

6. Davis, F.D.: Perceived Usefulness, Perceived Ease of Use, and User Acceptance of Information Technology. MIS Quarterly 13(3), 319-340 (1989) 
7. Davis, F.D., Bagozzi, R.P., Warshaw, P.R.: User Acceptance of Computer Technology: A Comparison of two Theoretical Models. Management Science 35(8), 982-1003 (1989)

8. Ganoe, C.H., Somervell, J.P., Neale, D.C., Isenhour, P.L., Carroll, J.M., Rosson, M.B., McCrickard, D.S.: Classroom BRIDGE: using collaborative public and desktop timelines to support activity awareness. In: Proc. of the ACM, UIST 2003, New York, pp. 21-30 (2003)

9. Hassenzahl, M., et al.: Hedonic and Ergonomic Quality Aspects Determine a Software's Appeal. In: Proc. CHI 2000 Conf. Human Factors in Computing, pp. 201-208. ACM Press, Addison-Wesley, New York (2000)

10. Hassenzahl, M., Beu, A., Burmester, M.: Engineering Joy. IEEE Software 18(1), 70-76 (2001)

11. Hassenzahl, M., Burmester, M., Koller, F.: Attrakdiff: Ein Fragebogen zur Messung wahrgenommener hedonischer und pragmatischer Qualität. In: Proc. Mensch \& Computer, pp. 187-196 (2003)

12. van der Heijden, H.: User acceptance of hedonic information systems. MIS Quarterly 28(4), 695-704 (2004)

13. Hollnagel, E.: Keep Cool: The Value of Affective Computer Interfaces in a Rational World. In: Proc. HCI Int'1 1999, vol. 2, pp. 676-680. Lawrence Erlbaum, Mahwah (1999)

14. Huang, M.-H.: Designing website attributes to induce experiential encounters. Computers in Human Behavior 19(4), 425-442 (2003)

15. Huang, E.M., Mynatt, E.D., Trimble, J.P.: When design just isn't enough: the unanticipated challenges of the real world for large collaborative displays. Personal Ubiquitous Computing 11(7) (2007)

16. Igbaria, M., Schiffman, S.J., Wieckowski, T.J.: The Respective Roles of Perceived Usefulness and Perceived Fun in the Acceptance of Microcomputer Technology. Behaviour \& Information Technology 13(6), 349-361 (1994)

17. Izadi, S., et al.: The iterative design and study of a large display for shared and sociable spaces. In: Proc. of DUX 2005. ACM Press, New York (2005)

18. Merriam-Webster. Merriam-Webster's Collegiate Dictionary. Merriam-Webster Inc., Springfield (2003)

19. Moon, J.-W., Kim, Y.-G.: Extending the TAM for a World-Wide-Web Context. Information and Management 38(4), 217-230 (2001)

20. Mynatt, E.D., et al.: Flatland: New dimensions in office whiteboards. In: Proc. CHI 1999. ACM Press, New York (1999)

21. Novak, J.M.: Yours...Ours? Designing for Principal-Agent Collaboration in Interactive Value Creation. In: Proc. of Wirtschaftsinformatik 2009, Vienna (2009)

22. Novak, J., Schwabe, G.: Designing for reintermediation in the brick-and-mortar world: Towards the travel agency of the future. In: Electronic Markets, vol. 19(1). Springer, Heidelberg (2009)

23. Novak, J., Aggeler, M., Schwabe, G.: Designing Large-Display Workspaces for Cooperative Travel Consultancy. In: Proc. of CHI 2008, Florence, Italy. ACM Press, New York (2008)

24. Rodden, T., et al.: Designing novel interactional workspaces to support face to face consultations. In: Proc. CHI 2003, pp. 57-64 (2003)

25. Schrepp, M., Held, T., Laugwitz, B.: The influence of hedonic quality on the attractiveness of user interfaces of business management software. Interacting with Computers 18(5), 1055-1069 (2006)

26. Schwabe, G., Novak, J., Aggeler, M.: Designing the Tourist Agency of the Future. In: 21st Bled eConference on eCollaboration, Slovenia (2008) 
27. Stewart, J., Bederson, B.B., Druin, A.: Single display groupware: a model for co-present collaboartion. In: Proc. of CHI 1999. ACM Press, New York (1999)

28. Streitz, N.A., Geißler, J., Holmer, T.: Roomware for cooperative buildings: Integrated design of architectural spaces and information spaces. In: Streitz, N.A., Konomi, S., Burkhardt, H.-J. (eds.) CoBuild 1998. LNCS, vol. 1370, p. 4. Springer, Heidelberg (1998)

29. Tollinger, I., et al.: Collaborative knowledge management supporting mars mission scientists. In: Proc. CSCW 2004. ACM Press, New York (2004)

30. Venkatesh, V.: Creation of Favorable User Perceptions: Exploring the Role of Intrinsic Motivation. MIS Quarterly 23(2), 239-260 (1999)

31. Venkatesh, V., Morris, M.G., Davis, G.B., Davis, F.D.: User Acceptance of Information Technology: Toward A Unified View. MIS Quarterly 27(3), 425-478 (2003)

32. Wilson, S., Galliers, J., Fone, J.: Not all sharing is equal: the impact of a large display on small group collaborative work. In: Proc. CSCW 2006. ACM Press, New York (2006) 